\title{
PERFORMANCE OF FIBER OPTICAL SENSORS IN THE STRUCTURE OF CONCRETE DAMS TO DEAL WITH THE IMPACT ACTIONS (CASE STUDY: SEIMARE DAM)
}

\author{
Sarah BAKHTIARI ${ }^{1,{ }^{*}}$, Mohammad Ali NEKOOIE $^{2}$ \\ ${ }^{1}$ Civil Engineering, the Branch of Structure, Danesh Alborz University, Tehran, Iran. \\ ${ }^{2}$ Department of Civil Engineering, Danesh Alborz University, Tehran, Iran. \\ corresponding author: bakhtiarisara258@gmail.com.
}

\begin{abstract}
Due to the fact that dams are considered one of the strategic infrastructures of a country, it is very important to protect it against destructive acts. Accordingly, sensors were used at various points to record structural responses to the dam. Based on the questionnaires completed by experts, accuracy had the score of 3.8 so it was considered as the most important feature of the sensors and the optical fiber sensor with a mean score of 3.93 was selected as the best sensor type among the available ones. For this project, a questionnaire was prepared based on Likert scale and SPSS method was used in TOPSIS software. Then, Seimare concrete double curvature arch dam was simulated in ABAQUS 2017 software and the proper positioning of the sensors for optimum performance was determined based on Finite Element Method analysis and according to structural control criteria such as tension, displacement, strain, velocity and so one.
\end{abstract}

\author{
Keywords: \\ Destructive measures; \\ Fiber optic sensor; \\ Double curvature arch dam; \\ Finite element method.
}

\section{Introduction}

Considering the important role of recording accurate information in the development of engineering sciences, it was decided to record structural responses through the installation of accurate, highly sensitive optical fiber sensors [1]. The process of damage exploration strategy for engineering and aerospace infrastructures is considered as structural health monitoring (SHM) [2]. Thus, it will be possible to better protect existing dams and to use this information and experiences in the future projects. In order to properly integrate fiber optical sensors, considerations such as proper installation and implementation, availability for repair and maintenance, time, cost, etc. should be considered [3]. But all of these factors are affected by the critical structural points which are under load. Therefore, the dam model was modeled using numerical methods and finite element software to determine the critical structural points [4]. This research is an attempt to determine the structural response control points against the surface explosion load near the dam, to determine the location of installing the fiber optic sensors.

Since the invention of the laser in 1960, and the emergence of modern fiber optic in 1966, it has always been tried to transfer the technology of optical fibers from the laboratory and change it into a practical technology [5]. Initially, the focus was on the ability of fiber optic to transfer information to telecommunication projects, but in the early 1970, some experiments on low- loss fiber optic showed that these fibers could also be used as sensors. From that time on, the technology and the use of fiber optic sensors (FOS) have grown increasingly [6]. In 2010 Shen et al. examined the performance of these sensors in the structure against the effect of the earthquake and the damage caused to the structure [7]. In 2001 Tennyson and Mufti dynamically and statically compared the structural health monitoring systems on bridges and dams, which have fiber optic sensors, with structures that were not equipped with this system [8]. In 2008 Draganić et al. examined the blast load on the structures and 
studied and proposed software to simulate an explosion impact [9]. In 2013 Rosolem et al. suggested fiber ring sensors with elastomeric coating for dam, which can be installed any time it is required [10]. Also, its installations easy and inexpensive.

\section{Methodology}

\subsection{Specifications of dam and blast}

The model used is the Seimare double arc concrete dam that the specifications of which are described in Table 1. Surface blast near the bottom of the dam is considered. Specifications relating to the blast are given in Table 2.

Table 1: Specifications of the Seimare Dam.

\begin{tabular}{|c|c|}
\hline Dam type & double arc concrete dam \\
\hline Height above foundation & $180 \mathrm{~m}$ \\
\hline Crest length & $202 \mathrm{~m}$ \\
\hline Foundation width & $28 \mathrm{~m}$ \\
\hline Crest width & $6 \mathrm{~m}$ \\
\hline
\end{tabular}

Table 2: Specifications of blast loading.

\begin{tabular}{|c|c|}
\hline Volume of TNT equivalent & 5 tones \\
\hline Type of blast & Surface - close \\
\hline $\begin{array}{c}\text { The arrival time of the wave to the } \\
\text { structure }\end{array}$ & $0 \mathrm{~s}$ \\
\hline Duration of blast & $3 \mathrm{~ms}$ \\
\hline
\end{tabular}

\subsection{Geometry of finite element model}

The Seimare double arc concrete dam was modeled using ABAQUS 2017 software and details are shown in Fig. 1.

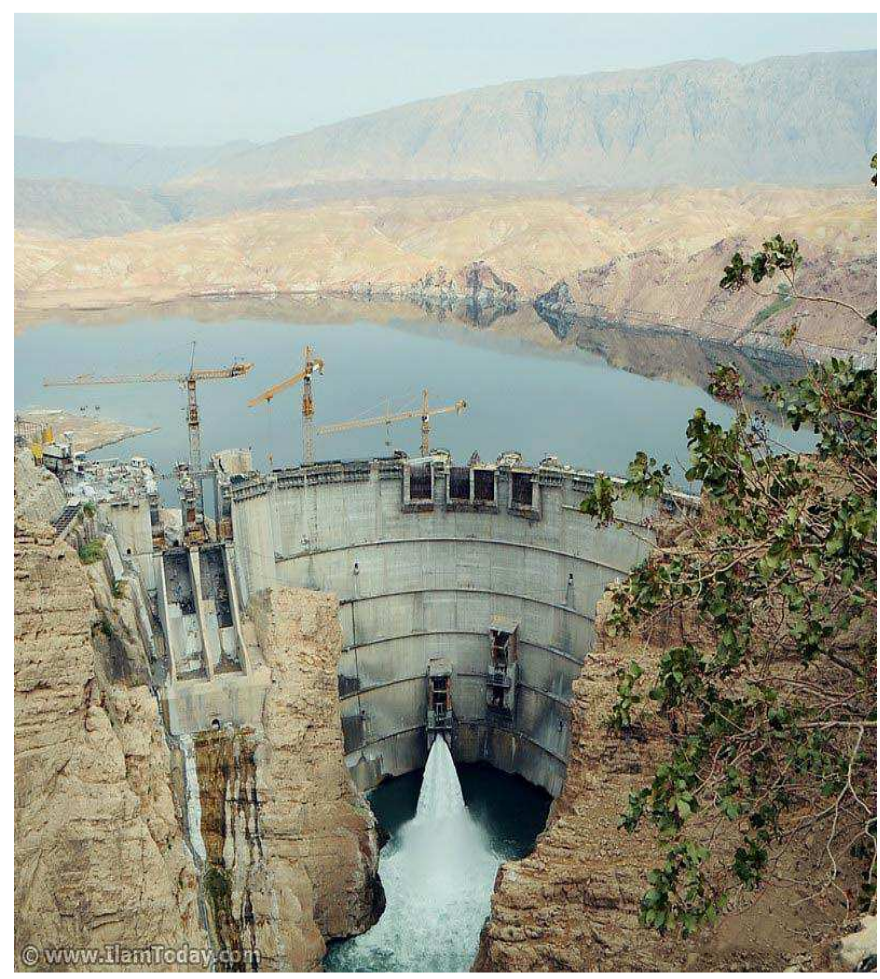

Fig. 1: Seimare dam, double arc concrete dam. 
Fig. 2 shows the geometry of the dam from above. The explicit analyzer has been used to solve the problem. The air volume around the structure is explicitly meshed and included in the finiteelement simulation.

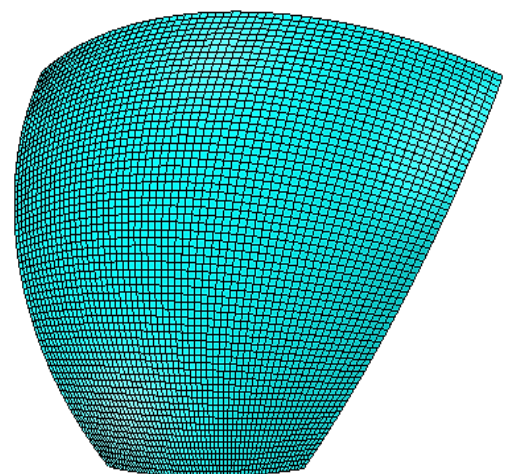

Fig. 2: The geometry of the finite element model of the dam.

\section{Results}

The explosion can be described as the heaviest and most unknown loading that can be entered into the structure. Due to the near-surface blast of 5 tons of TNT, the values of structural responses after the dynamic analysis in ABAQUS software are extracted as follows.
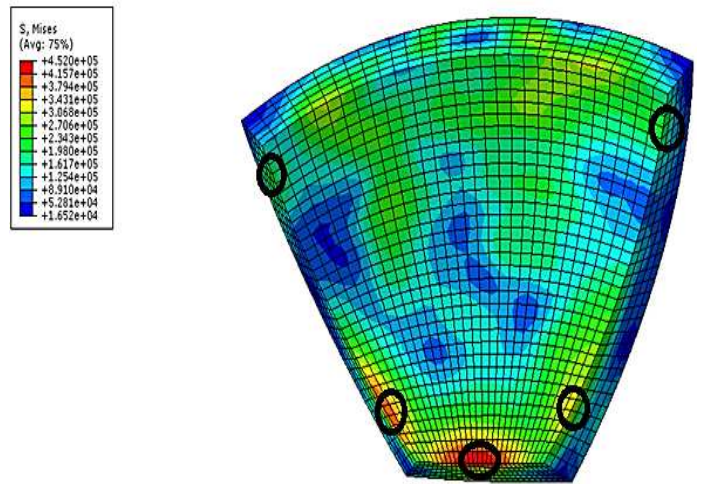

Fig. 3: Stress counter on structure after the explosion [MPa].

As shown in Fig. 3, the stress concentration is at the lowest level of the structure and the side supports of the dam.
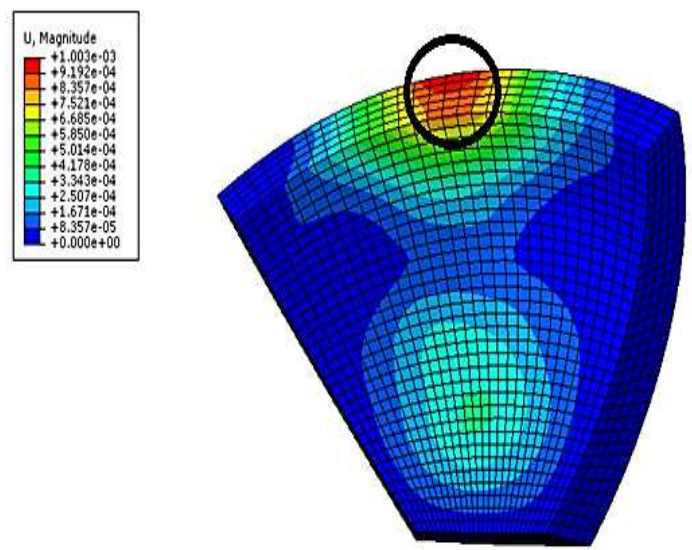

Fig. 4: Displacement counter on structure after the explosion [cm].

According to Fig. 4, the highest point of crest of the dam is determining based on the displacement control. 


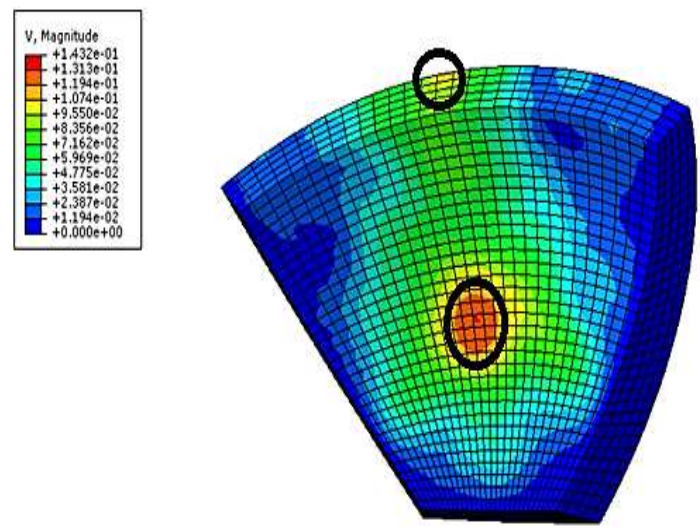

Fig. 5: Speed counter on structure after the explosion $[\mathrm{cm} / \mathrm{s}]$.

Fig. 5 shows that after dynamic analysis of the finite element model, the velocity is at the midpoint of the height and crest of the dam is at maximum level.
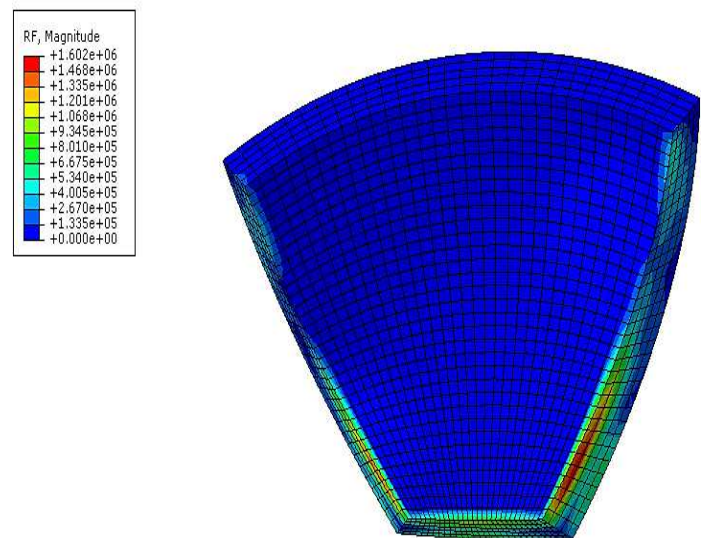

Fig. 6: The counter of reservoir - dam interactions after the explosion.

As can be seen in Fig. 6, the forces are concentrated in the side and bottom sections of the dam.

\section{Discussion and conclusion}

According to the software outputs and their analysis, we can determine the appropriate locations to embed fiber optic sensors in the structures. This location is based on the focus of structural responses at different points in the structure. By analyzing and comparing the results, it can be said that the lateral backrests (in terms of stress concentration), the dam crest (in terms of maximum displacement) and the midpoint of the dam for controlling the speed, can be optimal for the fitting of sensors.

Based on these calculations and comparison of the results, for optimal use of sensors, according to the output results, at least 7 sensors are required for installation in different locations and the desired performance. Of course, in this placement, should be considered the optimum intervals and the minimum required distance, since the installation of sensors, without observing the minimum and maximum distances, can cause possible impairment in their performance. The placement of sensors in the structure also follows other factors, including economic considerations, runtime, access to repair and maintenance, etc. However, these factors can be in the second priority after structural analysis. The installation points of the sensors in Fig. 7 are fully visible. 


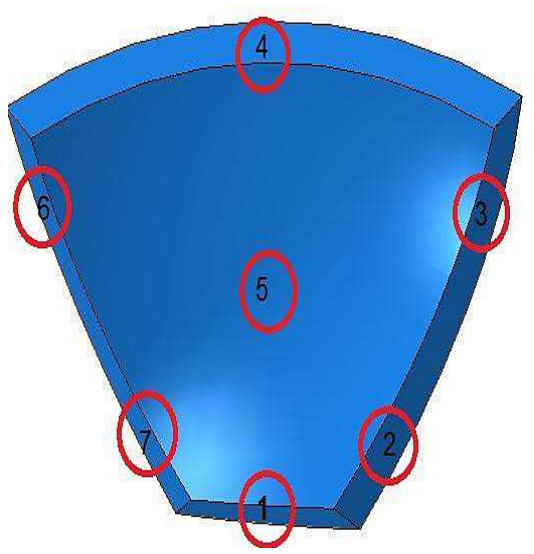

Fig. 7: Combining all control points to replace the sensor.

Fig. 7 shows that the control points are cumulatively. In this figure, points $1-2-3-6$ are based on the tensile criterion, point 5 is based on the speed criterion and point 4 based on the displacement criterion. It is mentioned previously that optical fibers can be used to discover and concentrate structural damages. Combining optical fiber outputs with a mechanical model is valuable for quantifying the damage. Fiber optical sensors as a kind of sensors can be multiplexed and against the electromagnetic effects are immune. Their benefits include non-conducting, small in size, reliable, low cost, lightweight, and non-corrosive. Moreover, they can tolerate high temperatures. In this research, distributed vibrational (accelerometers) fiber sensors are used and coverage with high location accuracy using standard communication fibers, which can be imbedded in different structures such as bridges, buildings, dams, power generators, and other civil works, to report their internal status in real time. Despite the advantages of fiber optics, the splice of optical fibers is difficult and there is loss of the light in the fiber due to scattering.

Regarding the control of the reservoir -dam interaction, the points 2 and 7, which are derived from the tensile criterion, confirm these points and the point 4 in the criterion of displacement and the speed is similar. It should be noted, however, that these points actually represent a range, and the sensor can be embedded in the surface of the circles shown in Figure 7. Furthermore, different parameters are affecting the nonlinear response of concrete dams. Increase in the height of concrete gravity dam leading to the increase in reservoir reduction effects. The condition along the damreservoir interface can be determined by supposing that the dam to vibrate with an acceleration of $u_{g}(t)$ as:

$\frac{\partial p}{\partial n}=-p_{f 0}\left(u_{g}+u_{a}\right)=-p_{f 0}\left(u_{\text {total }}\right)_{n}$,

where $p, u_{g}, u_{a}$ are pressure, ground acceleration, nodal acceleration created by the flexible dam, respectively and $n$ is the normal to the interface. In above equation, the value of $n$ is constant. It is obvious that in the surface of fluid-structure, there is not flow along the interface. This phenomenon resulted to condition that there is no relative velocity at the normal direction. In summary, the velocity of the structure and fluid on the interface are equal.

\section{References}

[1] BAO, X. - CHEN, L.: Recent progress in distributed fiber optic sensors. Sensors, Vol. 12, 2012, pp. $8601-8639$

[2] FARRAR, C. R. - WORDEN, K.: An introduction to structural health monitoring. Philos. Trans. A. Math. Phys. Eng. Sci., Vol. 365, 2007, pp. 303 - 315.

[3] LYNCH, J. P. - LOH, K. J.: A summary review of wireless sensors and sensor networks for structural health monitoring. Shock Vib. Dig., Vol. 38, 2006, pp. 91 - 130.

[4] TENNYSON, R. C. - COROY, T. - DUCK, G. - MANUELPILLAI, G. - MULVIHILL, P. - COOPER, D. J. F.: Fibre optic sensors in civil engineering structures. Can. J. Civ. Eng., Vol. 27, 2000, pp. 880 $-889$.

[5] LI, H. N. - LI, D. S. - SONG, G. B.: Recent applications of fiber optic sensors to health monitoring in civil engineering. Eng. Struct., Vol. 26, 2004, pp.1647 - 1657. 
[6] BARRIAS, A. - CASAS, J. R. - VILLALBA, S.: A review of distributed optical fiber sensors for civil engineering applications. Sensors (Basel), Vol. 16, 2016, pp. 1 - 35.

[7] SHEN, S. - WU, Z. - YANG, C. - WAN, C. - TANG, Y. - WU, G.: An improved conjugated beam method for deformation monitoring with a distributed sensitive fiber optic sensor. Struct. Health Monit., Vol. 9, 2010, pp. 361 - 378.

[8] TENNYSON, R. C. - MUFTI, A. A. - RIZKALLA, S. - TADROS, G. - BENMOKRANE, B.: Structural Health Monitoring of innovative bridges in Canada with fiber optic sensors. Smart Mater. Struct., Vol. 10, 2001, pp. 560 - 573.

[9] DRAGANIĆ, H. - SIGMUND, V.: Blast loading on structures. Technical Gazette, Vol.19, 2012, pp. $643-652$.

[10] ROSOLEM, J. B. - DINI, D. C. - PENZE, R. S. - FLORIDIA, C. - LEONARDI, A. A.: Fiber Optic Bending Sensor for Water Level Monitoring, Development and Field Test, A Review. IEEE Sensors Journal, Vol. 13, 2013, pp. 4113 - 4120. 